\title{
RNase mitochondrial RNA processing correctly cleaves a novel $R$ loop at the mitochondrial DNA leading-strand origin of replication
}

\author{
Daniel Y. Lee and David A. Clayton ${ }^{1}$ \\ Department of Developmental Biology, Beckman Center for Molecular and Genetic Medicine, Stanford University School of \\ Medicine, Stanford, California 94305-5427 USA
}

\begin{abstract}
The precursor primer RNA for mammalian mitochondrial DNA leading-strand replication remains as a persistent $R$ loop formed during transcription through the mitochondrial DNA control region. We have examined model $R$ loops, which exist in a novel and physiologically accurate preprimer conformation, as potential substrates for mammalian RNase mitochondrial RNA processing (MRP). Mouse RNase MRP accurately cleaves an R loop containing the mouse mitochondrial DNA origin. The multiple cleavage sites on the R-loop substrate match the priming sites observed in vivo, suggesting that RNase MRP alone is capable of generating virtually all of the leading-strand replication primers.
\end{abstract}

[Key Words: Replication priming; mitochondrial RNA processing; R loop; RNA-DNA hybrid; RNase MRP]

Received December 19, 1996; revised version accepted January 30, 1997.

Mammalian mitochondrial DNA (mtDNA) replicates by a mechanism of unidirectional displacement synthesis initiating from two distinct origins, one for each strand of the duplex circular genome (Clayton 1982). The mtDNA heavy $(\mathrm{H})$-strand is synthesized first, giving rise to the so-called displacement-loop (D-loop) DNA strand. Examination of the nucleic acid species from the $\mathrm{H}$-strand origin $\left(\mathrm{O}_{\mathrm{H}}\right)$ of human and mouse mtDNAs revealed discrete groups of light (L)-strand transcripts /so named because the L-strand served as template) that terminated precisely where $\mathrm{H}$-strand synthesis initiated (Gillum and Clayton 1979; Chang and Clayton 1985; Chang et al. 1985). In mouse mitochondria, some of the newly synthesized DNA strands were found to contain RNA chains covalently attached at their $5^{\prime}$ termini (Chang et al. 1985). These RNA species were shown to have the same 5' termini, which mapped exactly to the L-strand transcriptional promoter (LSP). Therefore, products of transcription were proposed to prime DNA synthesis at the mtDNA $\mathrm{O}_{\mathrm{H}}$. Because the L-strand transcripts extended beyond the replication origin, the action of a site-specific endoribonuclease was postulated to generate the mature primer RNA $3^{\prime}$ termini. The in vivo mapping data, which document the RNA to DNA transition sites with nucleotide-level precision, provided an

\footnotetext{
${ }^{1}$ Corresponding author. Present address: Howard Hughes Medical Institute, Chevy Chase, Maryland 20815-6789 USA.

E-MAIL claytond@hhmi.org; FAX (301) 215-8828.
}

excellent opportunity for investigating the RNA processing mechanism in vitro.

RNase mitochondrial RNA processing (MRP), a ribonucleoprotein (RNP) endoribonuclease, was originally described as an RNA processing activity purified from mouse mitochondrial extracts that cleaved singlestranded L-strand RNA in vitro at only one of the multiple in vivo priming sites (Chang and Clayton 1987a,b). Despite the precision of the RNA cleavage reaction, an issue relating to the substrate structure remained unresolved. Although primer RNAs were known to be associated stably with mtDNA when isolated from mitochondria, simple linear RNA-DNA heteroduplex substrates constructed with the primer RNA and its cDNA were not cleaved by RNase MRP (Chang and Clayton $1985,1987 b)$. However, it has become clear recently that such RNA-DNA heteroduplexes do not represent the physiological state of the preprimer complex, prompting us to re-evaluate the substrate specificity in the RNase MRP processing model.

$\mathrm{Xu}$ and Clayton $(1995,1996)$ reported that transcription by mitochondrial RNA polymerase through the replication control regions of yeast and human mtDNA resulted in persistent RNA-DNA hybrids also known as R loops. We have shown recently that model $\mathrm{R}$ loops like those formed via transcription can be reconstituted by hybridizing the L-strand RNA and its corresponding supercoiled DNA template in the presence of formamide (Lee and Clayton 1996). Distinct from simple RNAcDNA heteroduplexes, three-stranded $\mathrm{R}$ loops thus 
formed were remarkably stable and exhibited unusual structural properties that were proposed to be important in primer RNA metabolism. These findings provided crucial insight into defining a physiologically accurate preprimer complex as a potential substrate for an RNA processing enzyme. We now report the surprising finding that mouse RNase MRP cleaves R-loop substrates in vitro at virtually all of the priming sites observed in vivo, including the major sites of RNA to DNA synthesis that collectively constitute the leading-strand replication origin.

\section{Results}

The mouse R-loop substrate is processed by RNase $M R P$

RNase MRP was purified from mouse LA9 cells by methods described previously (Chang and Clayton 1987a,b) with additional chromatographic steps (see Materials and Methods). Enzymatic activity was followed by RNA cleavage with the standard single-stranded L-strand RNA substrate and by direct quantitation of the RNA subunit of RNase MRP. From the final ion exchange (Mono Q) chromatography, a single fraction corresponding to the peak of activity was used, unless stated otherwise. These highly purified enzyme fractions contained no detectable levels of nonspecific exonuclease, ribonuclease, and deoxyribonuclease activities under our standard reaction conditions. The model R-loop substrate containing the mouse mtDNA $\mathrm{O}_{\mathrm{H}}$ region (Fig. $1 \mathrm{~A}, \mathrm{~B})$ was prepared by annealing a transcript synthesized in vitro from pMR718B (Chang and Clayton 1987a) and the same supercoiled template DNA in the presence of formamide as described elsewhere (Lee and Clayton 1996).

A characteristic feature of persistent $\mathrm{R}$ loops generated either by transcription or reconstituted in formamide is the discrete and limited position of the RNA-DNA basepaired region (Lee and Clayton 1996; $\mathrm{Xu}$ and Clayton 1996). When the final Mono Q fractions were assayed with the R-loop substrate in which the RNA was uniquely radiolabeled at the 3 ' terminus, multiple cleavage products were observed (Fig. 2C). This R-loop processing activity coeluted with the standard singlestranded RNA cleavage activity (Fig. 2B) and with the RNA subunit of the RNase MRP holoenzyme (Fig. 2A). Comparison of the relatively simple RNase MRP cleavage pattern on the free RNA substrate to the more complex pattern on the $\mathrm{R}$ loop revealed similar overall reaction kinetics (Fig. 2D). However, cleavage at the major site on the free RNA, located between conserved sequence block (CSB)II and CSBIII, was less efficient in the $\mathrm{R}$ loop, and what was observed initially as inefficient cleavage at other discrete sites on the free RNA was highly enhanced in the R-loop substrate. This similarity in the cleavage pattern was accentuated with extended digestion times, suggesting that the RNA strand exhibits certain structural features of the $\mathrm{R}$ loop even in the absence of DNA (Fig. 2D). This observation is consistent

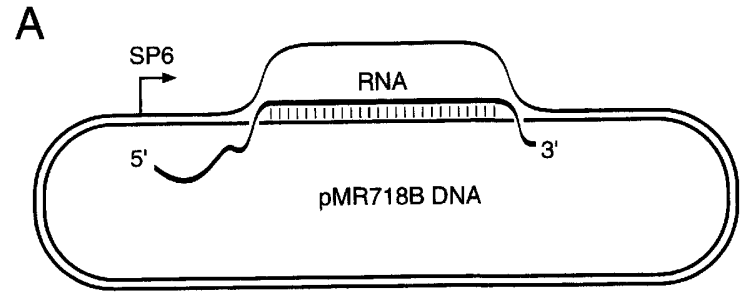

B

5' GAAUACACGG AAUUCGAGCU CGCCCACUAA AAUAUAAGUC

AUAUUUUGGG AACUACUAGA AUUGAUCAGG ACAUAGGGUU

UGAUAGUUAA UAUUAUAUGU CUUUCAaGUU CUUAGUGUUU

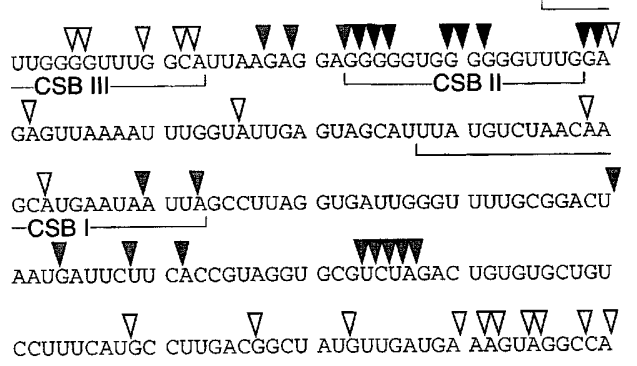

AAAUAAAAAG AUACCAAA $3^{\prime}$

Figure 1. Structure of the R-loop substrate. $|A|$ Diagram of the reconstituted $\mathrm{R}$ loop containing the mouse mtDNA control region. The double-stranded supercoiled plasmid (pMR718B) and the single-stranded RNA derived from the same template by in vitro transcription (SP6 RNA polymerase) is base-paired with the complementary DNA strand in a complex configuration. $(B)$ Nucleotide sequence of the RNA in the R-loop substrate. Conserved sequence blocks (CSB) are designated with brackets and sites of $E$. coli RNase $\mathrm{H}$ cleavage are denoted with arrowheads (Lee and Clayton 1996). Filled, hatched, and open arrowheads represent, respectively, strong, intermediate, and weak RNase $\mathrm{H}$ cleavage at that site, indicating the nonuniform RNA-DNA base-pairing throughout the length of the RNA. The $5^{\prime}$ region of the RNA strand that is largely unstructured is designated by italic text.

with the gross similarity of the free and R-loop forms of the primer RNA as determined by structural probing assays (Lee and Clayton 1996).

To confirm that these cleavage reactions were catalyzed by RNase MRP, we carried out specific inhibition experiments by exploiting the known ribonucleoprotein composition of the holoenzyme. The requirement of an RNA component of RNase MRP was shown previously by loss of cleavage activity upon digestion with micrococcal nuclease (Chang and Clayton 1987a). Consistent with these previous results, pretreatment of the Mono $Q$ fraction with micrococcal nuclease (with $\mathrm{Ca}^{2+}$, an essential metal cofactor) abolished cleavage at all sites on the R-loop substrate (Fig. 3A, lane 7); micrococcal nuclease with EGTA-chelated $\mathrm{Ca}^{2+}$ had no effect (Fig. 3A, lane 8). Predigestion of the Mono $\mathrm{Q}$ fraction with proteinase $\mathrm{K}$ 
Figure 2. R-loop processing activity of RNase MRP. (A) Purification profile of RNase MRP holoenzyme. The RNA subunit of RNase MRP was extracted from Mono $Q$ column fractions (numbers at top of lanes). RNAs were labeled with $5^{\prime}$ $\left[{ }^{32} \mathrm{P}\right] \mathrm{pCp}$ and T4 RNA ligase and resolved on a $6 \%$ polyacrylamide $/ 8 \mathrm{M}$ urea (denaturing) gel. RNase MRP RNA, which peaks at fractions $50-52$, is designated MRP. The larger RNA species is the RNA subunit of mouse RNase P (asterisk). (B) Standard single-stranded LSP transcript cleavage assay of the Mono $Q$ fractions. Substrate (S) was radiolabeled at the $3^{\prime}$ terminus and reaction products were resolved on a $6 \%$ denaturing polyacrylamide gel. The reaction product $(\mathrm{P})$ represents the $3^{\prime}$ fragment resulting from a unique cleavage site. Control (lane C) was reaction with no added enzyme. (C) RNA processing assay with the R-loop substrate. The chromatographic profile of the multisite R-loop cleavage activity parallels the singlestranded RNA processing activity. The peak of activity is again observed at fractions 50-52. Control (lane C) was reaction with no added enzyme. $(D)$ Digestion kinetics of the free RNA and R-loop substrates. The single-stranded RNA (ssRNA) and R-loop substrates of identical specific radioactivity were incubated with the same amount of the Mono $Q$ fraction under standard reaction conditions for various times (0.5-120 min). Mock reaction controls $(C)$ and size markers (M) are shown; markers are the Hpall-digestion fragments of pBR322.

also resulted in complete loss of activity, indicating the active form of the enzyme to be a ribonucleoprotein complex (Fig. 3B, lane 3).

The Th/To class of human antisera from patients with certain clinical autoimmune syndromes was shown previously to immunoprecipitate the RNase MRP ribonucleoprotein and thereby deplete enzymatic activity /Gold et al. 1989; Karwan et al. 1991). When the Mono Q fraction was subjected to precipitation with $\mathrm{Th} / \mathrm{To} \mathrm{immu}$ noglobulins adsorbed on protein A (Staphylococcus aureus|-Sepharose beads, the resulting supernatant was no longer active for R-loop processing (Fig. 3C, lane 4). In contrast, the same treatment of the Mono $Q$ fraction with serum from a normal subject, or the protein A-Sepharose beads alone, had no effect on the processing activity (Fig. 3C, lanes 5 and 3, respectively).

A specific oligonucleotide directed against the RNA component of the enzyme (oligo $2 \mathrm{C}$ ) was shown previously to interfere with enzymatic activity (Chang and Clayton 1987a). We demonstrate that another specific antisense oligonucleotide (oligo LRI), designed to basepair with the RNase MRP RNA subunit at one of its most conserved domains [termed long-range interaction region I (Schmitt et al. 1993)], inhibits the RNA cleavage reaction with improved effectiveness. To confirm the target specificity of the oligonucleotide, the RNA subunit of RNase MRP extracted from the Mono Q fraction was digested with RNase $\mathrm{H}$ from Escherichia coli in the presence of excess oligo LRI (Fig. 4A, lane 3). When oligo LRI was preincubated with the Mono $Q$ fraction and then assayed with the R-loop substrate, the cleavage reaction was inhibited in a concentration-dependent manner (Fig. 4B). This antisense oligonucleotide inhibited cleavage by $50 \%$ at a concentration of $\sim 4 \mu \mathrm{M}$ (lane 4 ) and was almost completely inhibitory at $\sim 40 \mu \mathrm{M}$ (lane 5 ). Oligo P (complementary to the mouse RNase P RNA subunit) and oligo $5.8 \mathrm{~S}$ (complementary to mouse 5.8S rRNA) were used as negative controls in E. coli RNase $\mathrm{H}$ digestions (Fig. 4A) and in substrate cleavage inhibitions. Neither of these oligonucleotides inhibited RNase MRP activity in the concentration range tested (oligo $5.8 \mathrm{~S}$ data are shown in Fig. 4C). Moreover, oligo LRI did not inhibit cleavage of a pre-tRNA ${ }^{\text {Ser }}$ species by RNase $P$ at concentrations up to $40 \mu \mathrm{M}$ (data not shown), further excluding RNase $\mathrm{P}$ as a participant in the cleavage reaction. We conclude from these and the above results that RNase MRP is catalyzing site-specific cleavage of the R-loop substrate.

\section{Analysis of cleavage products}

To determine whether each cleavage product resulted from an endonucleolytic event, we performed identical RNase MRP digestions of the R-loop substrate in which the RNA strand was uniquely labeled at the $5^{\prime}$ terminus. Each of the cleavage sites observed on the $3^{\prime}$ end-labeled $\mathrm{R}$ loop had a corresponding site on the $5^{\prime}$ end-labeled substrate, confirming that each product resulted from an endonucleolytic mode of hydrolysis (Fig. 5A). High-resolution mapping of the RNase MRP cleavage sites was achieved by resolving the digestion products next to RNA enzymatic sequencing ladders (Fig. 5B). Examination of the sequence at and surrounding each cleavage site revealed no apparent consensus enzyme recognition sequence. However, comparisons of the in vitro cleavage sites to the positions of priming sites mapped previously 
A

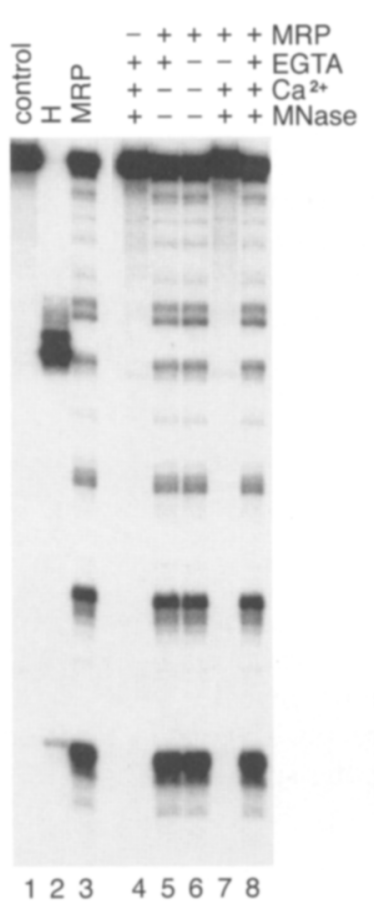

B

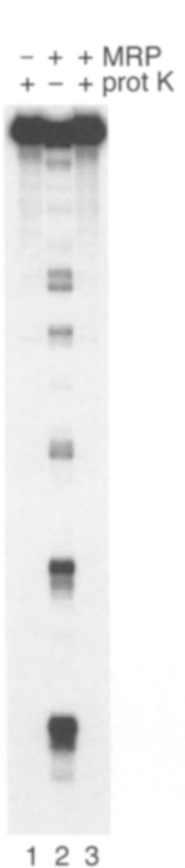

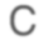

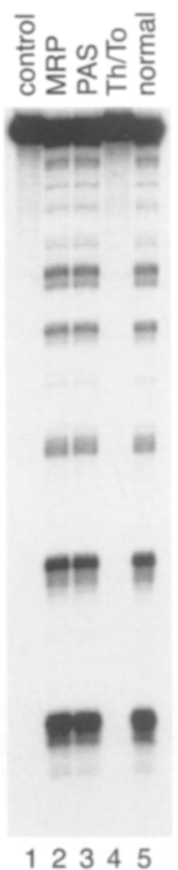

These results suggest that our reconstituted in vitro RNA processing system accurately reproduces the reaction that occurs in vivo.

Despite the precision of the RNase MRP cleavage site selection, the relative reaction efficiency at each cleavage site does not correspond strictly with the relative abundance of the multiple RNA termini observed in
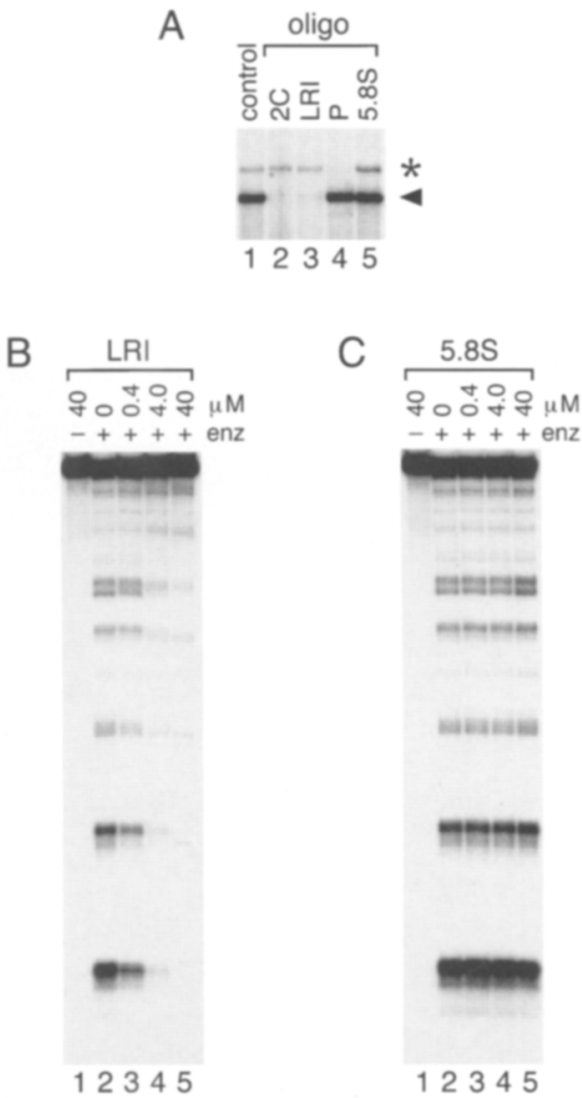

Figure 4. Antisense oligonucleotide interferes with R-loop processing activity. (A) Sequence-specific RNA digestions with E. coli RNase $\mathrm{H}$ and antisense oligonucleotides. Total RNA was purified from Mono Q fraction 52 and labeled with $5^{\prime}\left[{ }^{32} \mathrm{P}\right] \mathrm{pCp}$ and bacteriophage T4 RNA ligase. Excess oligonucleotides were added, heat denatured, and slowly cooled to permit annealing, followed by the addition of E. coli RNase $\mathrm{H}$. Products were resolved in a $6 \%$ denaturing polyacrylamide gel. Oligonucleotides 2C and LRI (lanes 2,3), which are both complementary to the 275-nucleotide MRP RNA, resulted in specific digestions (arrowhead). Oligonucleotides of unrelated sequence (P and $5.8 \mathrm{~S}$, lanes 4,5 , respectively) had no effect on the 275 -nucleotide RNA. Oligo $P$ is complementary to the mouse RNase P RNA subunit and results in specific RNase $\mathrm{H}$ digestion of the larger RNA species (asterisk). ( $B$ ) Oligo LRI inhibits R-loop processing activity. The Mono $\mathrm{Q}$ fraction was incubated with oligo LRI at concentrations from $0.4 \mu \mathrm{M}$ to $40 \mu \mathrm{M}$, followed by the addition of substrate (lanes 3-5). Oligo LRI alone at $40 \mathrm{~mm}$ was incubated with the R-loop substrate to confirm the absence of contaminants (lane 1). (Lane 2) Control reaction with no added oligonucleotide. $(C)$ The same concentration range of oligo $5.8 \mathrm{~S}$ (lanes 3-5) has no effect on the R-loop cleavage activity of the Mono Q fraction. 

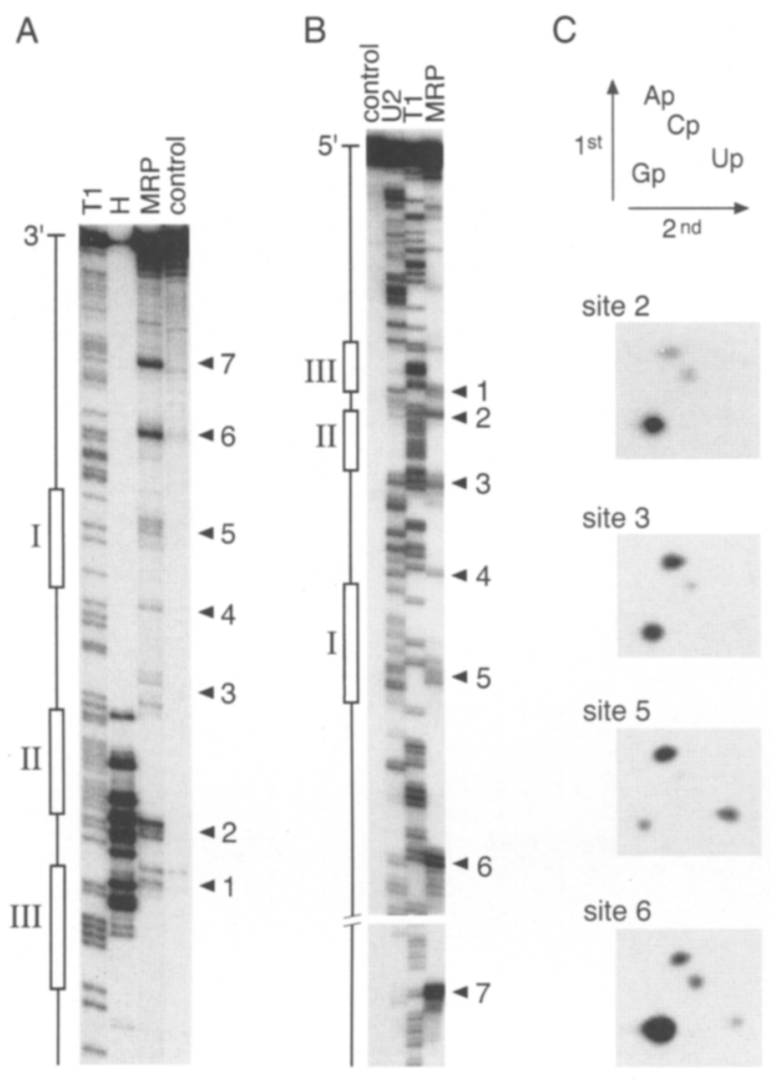

Figure 5. Analysis of R-loop cleavage products. $(A)$ RNA $15^{\prime}$ end-labeled) was assembled into an R-loop and digested with RNase MRP and E. coli RNase $\mathrm{H}$ as indicated above the lanes. Mock reaction control and RNA sequencing ladder generated with RNase $T_{1}$ (G-specific) are also shown. The major cleavage sites are denoted with arrowheads numbered 1 through 7. CSBs are diagrammed as boxes, indicating their relative positions next to the resolving gel. $\{B \mid$ High-resolution mapping of the RNase MRP cleavage sites. RNA ( $3^{\prime}$ end-labeled) reconstituted into an R-loop was digested with RNase MRP and resolved adjacent to RNA sequencing ladders generated with RNase $U_{2}$ (A-specific) and RNase $T_{1}$. Other sequencing ladders are omitted for clarity. (C) Analysis of the $3^{\prime}$-end-group of the RNase MRP cleavage products. Preparative-scale RNase MRP reactions were carried out and the products labeled with $5^{\prime}\left[{ }^{32} \mathrm{P}\right] \mathrm{pCp}$ and T4 RNA ligase. Labeled products were electrophoretically resolved and eluted, followed by quantitative hydrolysis with RNase $T_{2}$. The nucleoside-monophosphate products were resolved in two dimensions on precoated thin-layer plates. The positions of all four nucleoside- 3 '-monophosphates are indicated by the diagram at the top; analysis of four RNase MRP cleavage products are shown.

vivo. This difference could reflect the absence of mitochondrial nucleic acid-binding proteins in our assays that may alter the relative cleavage efficiencies at any particular site. Alternatively, the relative abundance of the in vivo RNA termini may not reflect the true RNA cleavage kinetics if the steady-state levels of each RNA species are determined by different rates of primer usage and turnover. Nonetheless, we suggest that the specificity of the R-loop cleavage reaction supports a role for
RNase MRP in mitochondrial primer RNA processing that can account for virtually all of the in vivo nucleic acid termini.

Close examination of the RNA sequencing autoradiographs revealed slightly altered mobilities of RNase MRP cleavage products relative to the ladders generated with RNases $T_{1}, U_{2}$, and Phy $M$ (from Physarum polycephalum), and RNase B. c. (from Bacillus cereus). These base-specific ribonucleases yield products with $3^{\prime}$ phosphate and 5' hydroxyl groups, suggesting that RNase MRP catalyzes RNA hydrolysis to produce 3 ' hydroxyl and $5^{\prime}$ phosphate termini. The $3^{\prime}$ termini of the RNase MRP cleavage products were analyzed for radioactive phosphate addition using $5^{\prime}\left[{ }^{32} \mathrm{P}\right] \mathrm{pCp}$ and bacteriophage T4 RNA ligase, followed by ribonucleoside analysis. Because T4 RNA ligase requires substrates with $3^{\prime}$ hydroxyl and 5' phosphate termini, successful pCp ligations should yield adducts with a single radioactive phosphorus at the $3^{\prime}$ position. Ligations of preparative scale R-loop cleavage reactions revealed that RNase MRP cleavage products were positive $\mathrm{pCp}$ acceptors (data not shown). To confirm the specificities of the li-

$$
\underset{\text { AUAUUUUGGG AACUACUAGA AUUGAUCAGG ACAUAGGGUU }}{\longrightarrow}
$$

UGAUAGUUAA UAUUAUAUGU CUUUCAaGUU CUUAGUGUUU
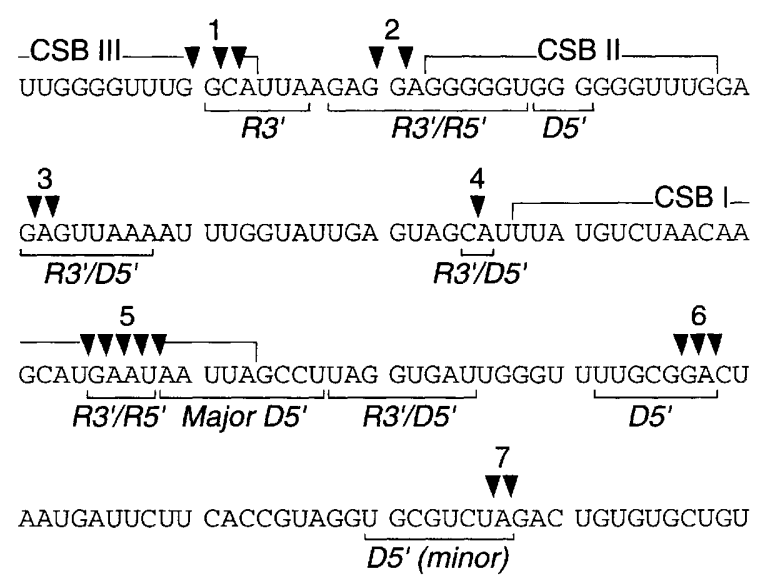

CCUUUCAUGC CUUGACGGCU AUGUUGAUGA AAGUAGGCCA

Figure 6. Positions of the RNase MRP cleavage sites. The LSP transcription initiation site (position 16,183 under numbering scheme of Bibb et al. 1981) is indicated with a bent arrow at the first nucleotide of the transcript $(+1)$. Positions of the multiple RNA to DNA transitions observed in vivo are designated with brackets below the sequence. The 3' termini of LSP transcripts $\left(\mathrm{R}^{\prime}\right)$, of RNA residues detected at the $5^{\prime}$ termini of nascent DNA strands $\left(\mathrm{R}^{\prime}\right)$, or the $5^{\prime}$ termini of nascent DNA strands (D5') are indicated. In vitro RNase MRP cleavage sites are shown as arrowheads and arbitrarily numbered from 1-7. CSBs are indicated with brackets above the sequence. 
gase acceptor ends, radioactive products that were resolved clearly in denaturing gels were subsequently eluted and digested to completion with RNase $T_{2}$. The resulting hydrolysate was then resolved by two-dimensional thin-layer chromatography to determine the nucleoside content at the $3^{\prime}$ termini of the processed RNA fragments (Fig. 5C). These results demonstrate that the 3 ' termini of the RNase MRP cleavage products are hydroxyl groups, fulfilling a necessary DNA polymerase substrate requirement.

\section{Template sequence requirements for $R$-loop processing}

It was shown previously that mutations in either CSBII or CSBIII resulted in loss of the persistent $\mathrm{R}$ loop formed during transcription (Xu and Clayton 1996). Such mutations also affected the ability to reconstitute stable $\mathrm{R}$ loops in vitro (Lee and Clayton 1996). In contrast, mutations within or a complete deletion of CSBI had only minor effects on the formation and stability of $\mathrm{R}$ loops generated by either method (Xu and Clayton 1996; D.Y. Lee and D.A. Clayton, unpubl.). However, mutations of CSBI in the R-loop substrate resulted in loss of virtually all of the RNase MRP cleavage sites (Fig. 7, lane 6). Furthermore, truncations at the $3^{\prime}$ terminus of the RNA that retain CSBI also abolish these cleavage sites (data not shown), indicating a requirement for a certain minimum length at the $3^{\prime}$ terminus or a specific region that includes CSBI and the nonconserved downstream sequence. In such mutations, the $E$. coli RNase $\mathrm{H}$ cleavages within CSBII were reduced in frequency and downstream cleavages were enhanced, indicating the alteration of the mutant R-loop structure (Fig. 7, cf. lanes 2 and 5). These results suggest that the particular conformation of the $\mathrm{R}$ loop at the $\mathrm{O}_{\mathrm{H}}$ region is important for substrate recognition. Because no RNase MRP cleavage activity was observed on other synthetic $\mathrm{R}$ loops assembled with nonorigin mtDNA sequences containing G-rich tracts or with completely unrelated plasmid sequences (data not shown), we conclude that the cleavage reaction is specific for the mtDNA $\mathrm{O}_{\mathrm{H}}$ sequence in the context of a distinct RNA-DNA hybrid configuration, which displays both duplex and single-strand nucleic acid properties.

\section{Discussion}

The initial steps in DNA replication involve regional duplex melting and primer synthesis, and both processes can be accomplished efficiently by the transcription machinery as exemplified by some well-studied prokaryotic systems such as the bacterial ColE1 replicon and bacteriophage T7 (Itoh and Tomizawa 1980; Romano et al. 1981; Fuller and Richardson 1985; vonMeyenburg et al. 1987; Masukata and Tomizawa 1990; Asai and Kogoma 1994). At the E. coli chromosomal origin, oriC, transcription has been shown to generate an $\mathrm{R}$ loop in the vicinity of the replication initiation site that facilitated dnaAcatalyzed melting of the DNA duplex under certain conditions (Baker and Kornberg 1988). However, DNA pri- mase was still required to initiate replication, because the transcription-derived RNAs were not utilized as primers (Baker and Kornberg 1988). At the mtDNA O $\mathrm{H}_{\mathrm{H}}$ a mechanism involving the action of a DNA primase is unlikely based on the length, structure, and sequence content of the primer RNAs (Chang and Clayton 1985; Chang et al. 1985). Because the LSP transcripts extend beyond the $\mathrm{O}_{\mathrm{H}}$ region and the resulting polycistronic RNA encodes functional products, a processing activity was proposed to generate the mature primer RNA termini for DNA replication (Fig. 8). Interestingly, the action of a mtDNA primase has been reported for the mtDNA L-strand origin $\left(\mathrm{O}_{L}\right)$. Mitochondrial DNA primase accurately synthesizes short oligoribonucleotides specifically on a single-stranded DNA template containing a phylogenetically conserved stem-loop secondary structure (Wong and Clayton 1986). Thus, the two origins of mammalian mtDNA appear to differ in genomic position, sequence content, timing of activation, and priming mechanisms.

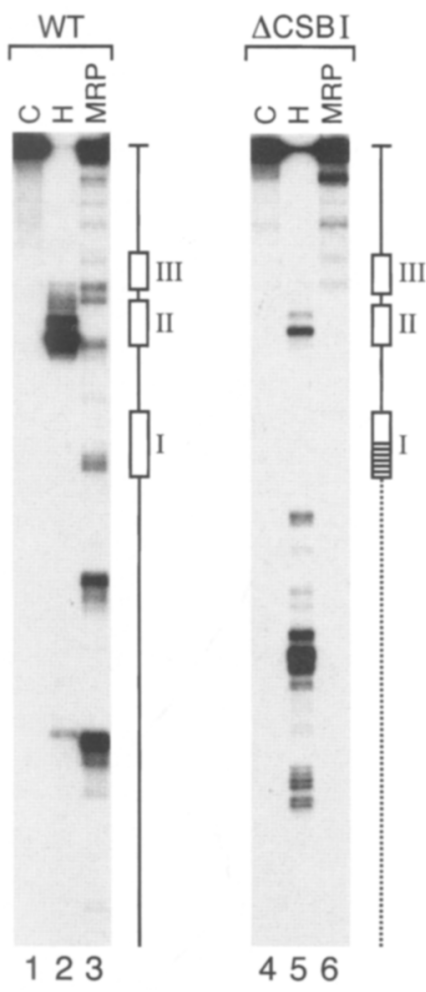

Figure 7. R-loop processing requires the sequence of the mouse mtDNA replication origin. The mouse mtDNA control region of pMR718B was mutated by deletion of a restriction fragment. The resulting mutated template ( $\triangle \mathrm{CSBI}$ ) contains unrelated vector DNA sequence beginning from the NlaIII site within CSBI as indicated by the hatched region of the diagram. RNA was synthesized from this template and assembled into an $\mathrm{R}$ loop as described. RNase MRP was added to the standard reaction mixture containing this mutated substrate (lane 6) or the wild-type $\mathrm{R}$ loop (lane 3). The RNA-DNA base-paired regions were assessed by digestion with $E$. coli RNase $\mathrm{H}$ (lanes 2,5). 
a

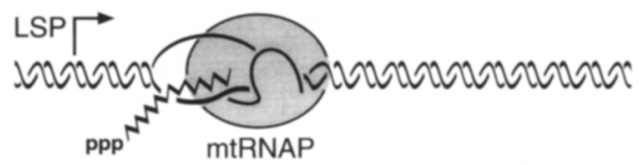

b

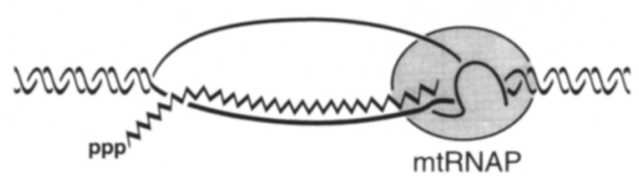

C

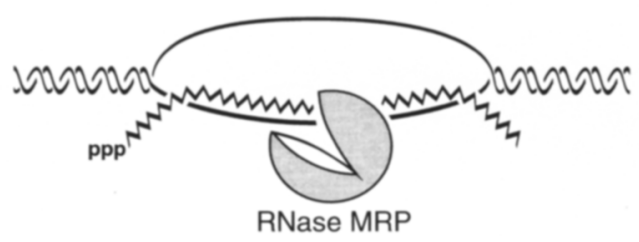

d

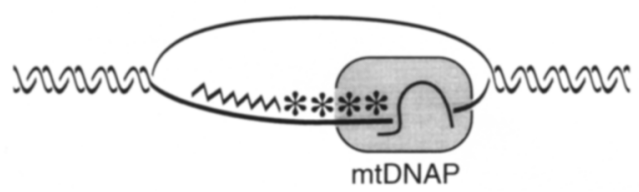

Figure 8. Model for activation of the mammalian mtDNA leading-strand replication origin. (a) A transcript synthesized by mitochondrial RNA polymerase initiates from the LSP. $(b)$ The nascent RNA chain remains stably associated with the DNA template as a persistent RNA-DNA hybrid giving rise to an R loop. (c) The $\mathrm{R}$ loop is a substrate for RNase MRP, which cleaves the RNA strand at multiple sites along the hybrid region, thereby generating properly annealed RNA primers. (d) DNA synthesis (asterisks), catalyzed by mtDNA polymerase, initiates by extension of mature RNA primers.

\section{A role for $R$ Nase $M R P$ in mitochondrial RNA processing}

Based on the discrete primer RNA termini, it is unlikely that an RNase $\mathrm{H}$ can generate the mitochondrial RNA primers observed in vivo. Although certain heteroduplexes of RNA and DNA within model "Okazaki" substrates are cleaved by mammalian RNase HI in a structure-specific manner, that reaction is dependent on extant RNA-DNA covalent linkages, suggesting a role in primer excision (Huang et al. 1994). The RNase $\mathrm{H}$ activity of HIV-1 reverse transcriptase (RT) also has been shown to exhibit a certain degree of specificity in cleaving the preprimer RNA in an RNA-DNA heteroduplex to generate mature primers, as well as to remove it once DNA synthesis has initiated (Huber and Richardson 1990). Whether RNase MRP can cleave at or near RNADNA covalent junctions is not known, but it would be of interest to examine its possible role in primer excision. Alternatively, a nonspecific mitochondrial RNase H-like activity may be required for primer RNA removal. The postulated action of such an enzyme could explain the abundance of the small polyadenylated RNA species observed in human mitochondria known as 7S RNA, whose $5^{\prime}$ terminus has been mapped to a location now known to be the start site of transcription from the LSP and its 3 ' terminus to a few nucleotides upstream of the major mtDNA H-strand initiation site /Ojala et al. 1981a).

Although the relatively small amount of RNase MRP found in isolated mitochondria has been argued to question its function in the organelle, several localization studies have indicated a mitochondrial presence (for review, see Clayton 1994). The clearly defined cytoplasmic presence of RNase MRP has been demonstrated recently in situ at high resolution (Matera et al. 1995; Lee et al. 1996), and the most reasonable interpretation of all of the available data is consistent with a mitochondrial presence of RNase MRP. Côté and Ruiz-Carrillo (1993) have reported that calf thymus endonuclease $G$ (endo $G$ ) can cleave double-stranded DNA, single-stranded DNA and RNA, and an RNA-DNA heteroduplex containing the mouse mtDNA control region. These authors proposed a role for endo $G$ in processing RNA primers for $H$-strand mtDNA synthesis. However, the potential cleavage sites in RNA do not match the pattern of in vivo priming sites and the issue of whether endo $G$ can function as an RNase $\mathrm{H}$ remains to be resolved (Clayton 1994). In contrast to the relatively nonspecific activity of endo G, RNase MRP has no detectable DNA nicking activity and is specific for primer transcripts whether as a free RNA (Chang and Clayton 1987b; Bennett and Clayton 1990) or in the unique R-loop configurations reported here.

The abundance of RNase MRP RNA in the nucleus and regulated expression studies have suggested its role in nuclear 5.8S rRNA processing (Schmitt and Clayton 1993; Clayton 1994; Chu et al. 1994; Lygerou et al. 1994). This possibility is supported by the demonstration of pre-rRNA processing in vitro with yeast RNase MRP (Lygerou et al. 1996). However, in vitro processing of yeast mitochondrial transcripts at a putative replication initiation site also supports a mitochondrial function (Stohl and Clayton 1992). Despite its abundance in the nucleolus, MRP RNA (also known as 7-2 RNA) is distinct from other small nucleolar RNAs (snoRNAs) characterized to date, which may reflect a more complex role in functions other than ribosome or rRNA metabolism (Balakin et al. 1996).

A dual role for RNase MRP in mitochondrial and nuclear RNA processing may suggest involvement in coordinating organellar and cellular biosynthetic activities. It is both curious and interesting that the highly conserved upstream regulatory regions of the mouse and human RNase MRP RNA genes have been shown to contain functional binding sites for NRF-1 (nuclear respiratory factor 1), a transactivator implicated in coordinating the expression of some nuclear-encoded respiratory chain subunits with mtDNA gene expression and replication (Evans and Scarpulla 1990; Virbasius et al. 1993). 
Not surprisingly, this element is also found in the upstream region of the gene encoding the principal human mitochondrial transcription factor, mtTFA (Virbasius and Scarpulla 1994). Further work in this area may provide important insight into the intracellular control of mitochondrial biogenesis.

\section{Substrate recognition by RNase MRP}

We have shown that RNase MRP can cleave the mitochondrial leading-strand primer RNA in the context of a triple-stranded R loop. Because the major R-loop cleavage sites are also detectable with extended reaction times as minor but reproducible sites on the free RNA (Fig. 2D), this substrate RNA presumably exists in equilibrium with a structurally identical form of the R loop, even in the absence of DNA. This hypothesis is supported by structural probing data that indicate that the free RNA exhibits a highly folded conformation that is remarkably similar to the RNA in the R-loop complex (Lee and Clayton 1996). However, this specific conformation is dependent on the annealing of the RNA to the double-stranded DNA template under superhelical tension, because the same sequence in an RNA-cDNA heteroduplex does not exhibit the same structure (Lee and Clayton 1996). Previously, Brown et al. (1986) identified potential secondary structures within the control regions of several vertebrate mitochondrial genomes. In all cases, the $\mathrm{O}_{\mathrm{H}}$ region, spanning $\sim 100 \mathrm{bp}$ that included the $3^{\prime}$ half of CSBI and divergent downstream sequences, folded into tRNA-like cloverleaf structures. We suggest that these predicted secondary structures are consistent with the highly organized conformation of the $\mathrm{R}$ loop, and thus may explain the requirement for CSBI and the nonconserved downstream region of the substrate in RNase MRP processing (D.Y. Lee and D.A. Clayton, in prep.).

The potential tRNA-like structure at the $\mathrm{O}_{\mathrm{H}}$ region points to another issue which relates RNase MRP and RNase $\mathrm{P}$, the catalytic RNP that cleaves at the $5^{\prime}$ maturation site of precursor tRNAs (Robertson et al. 1972; Stark et al. 1978). Similar structural properties of the RNA subunits (Forster and Altman 1990; Schmitt et al. 1993), a shared antigenic determinant (Gold et al. 1989), structural association of the two enzymes in the nucleolus (Lee et al. 1996), and at least one common protein subunit between the two RNPs (Lygerou et al. 1994) all hint at an intriguing evolutionary and functional relationship. Genetic organization of mammalian mtDNA has suggested that processing of the polycistronic mitochondrial transcripts is accomplished largely by tRNA excision (Battey and Clayton 1980; Ojala et al. 1981b). In principle, the actions of RNase P and RNase MRP can produce the vast majority of the mature mitochondrial tRNAs, rRNAs, mRNAs, and replication primers. A partially purified mitochondrial RNase $P$ from human cells has been characterized in vitro and, like other counterparts, contains an RNA component essential for activity (Doersen et al. 1985). In contrast to the budding yeast, in which the RNA subunit of the mitochondrial RNase $\mathrm{P}$ is
mtDNA-encoded (Miller and Martin 1983), the mammalian RNA subunit must be a nuclear gene product that requires translocation into the organelle. It is not yet clear whether the major RNase P RNA in mammalian cells is also functional in mitochondria, but the observation of multiple isoforms of the RNase P RNA genes (Li and Williams 1995) suggests additional possibilities.

The R-loop processing data presented here underscore the importance of the substrate structure. Our proposed model for RNA priming at the mtDNA $\mathrm{O}_{\mathrm{H}}$ directly links transcription with DNA synthesis through the formation of a structurally complex R-loop preprimer intermediate. We have shown that the site-specific cleavage activity of RNase MRP can generate the majority of the $3^{\prime}$ primer termini observed in vivo. Based on these findings, we propose a role for mammalian RNase MRP in mitochondrial primer RNA maturation, a critical step in the initiation of leading-strand mtDNA replication.

\section{Materials and methods}

\section{Substrates}

The free RNA substrate was generated from pMR718B by transcription with bacteriophage SP6 RNA polymerase as described previously (Chang and Clayton 1987b; Lee and Clayton 1996). The CSBI-mutation substrate was constructed as follows. The 564-bp NlaIII fragment of pMR718B that contains the SP6 promoter and the mouse mtDNA sequence to the NlaIII site in CSBI (position 16,037) was blunt-ended with T4 DNA polymerase (Boehringer Mannheim) and ligated into the EcoRV site of pBluescript II KS (+). The resulting construct (pMR-Nla.3) was sequenced to confirm the orientation of the insert. pMR-Nla.3 was digested with AseI to generate a runoff transcript of 352 nucleotides by in vitro transcription with SP6 RNA polymerase. R-loop substrates reconstituted by the annealing of singlestranded RNA and supercoiled DNA templates in the presence of formamide are described elsewhere (Lee and Clayton 1996).

\section{RNase MRP purification}

Mouse LA9 cells (12-24 liters) in spinner cultures were harvested at late $\log$ phase at a density of $-7.5 \times 10^{5}$ cells $/ \mathrm{ml}$ (Tapper et al. 1983). Sucrose gradient-purified mitochondria were lysed with Triton X-100 and the high-speed supernatant (fraction I) was chromatographed on DEAE Sephacel (fraction II), phosphocellulose (fraction III), and heparin-Sepharose (fraction IV) as described (Chang and Clayton 1987b). RNase MRP activity was assayed in a reaction buffer containing $20 \mathrm{mM}$ Tris at $\mathrm{pH}$ 8.0, $10 \mathrm{mM} \mathrm{MgCl}_{2}, 50 \mathrm{mM} \mathrm{KCl}$, and $1 \mathrm{~mm}$ DTT. Between column steps, samples were desalted by gel filtration through a 1.5 $\mathrm{cm} \times 15 \mathrm{~cm}$ Sephacryl S-300 HR (Pharmacia) column and concentrated with Centriprep 30 ultrafiltration devices (Amicon). Active fractions were loaded on linear $15 \%-30 \%$ glycerol gradients in buffer $\mathrm{G}(20 \mathrm{~mm}$ Tris at $\mathrm{pH} 8.0,100 \mathrm{~mm} \mathrm{KCl}, 0.5 \mathrm{~mm}$ EDTA, $1 \mathrm{mM}$ DTT, $1 \mathrm{mM}$ PMSF| containing $1.0 \mathrm{ml}$ of $50 \%$ glycerol cushions. Gradients were centrifuged at 40,000 rpm for $16 \mathrm{hr}$ in a SW41Ti rotor at $4^{\circ} \mathrm{C}$, and $\sim 0.5-\mathrm{ml}$ fractions were collected by dripping from the tube bottom. Active enzyme fractions were pooled (fraction V) and passed through a $2.5 \times 40-\mathrm{cm}$ Sephacryl S-500 SF (Pharmacia) column in buffer Q $(20 \mathrm{~mm}$ Tris at $\mathrm{pH} 8.0,0.5 \mathrm{~mm}$ EDTA, $1 \mathrm{~mm}$ DTT) containing $150 \mathrm{~mm} \mathrm{KCl}$. The activity was recovered in the void volume (fraction VI), indicating its large apparent molecular mass. The collected 
samples were passed through $0.2-\mu \mathrm{m}$ cellulose acetate syringe filters prior to loading on a FPLC Mono Q HR 10/10 column (Pharmacia) in buffer $Q$ essentially as described /Chang and Clayton 1987a). RNase MRP activity was eluted with a 200-ml linear salt gradient from 0.15 to $0.75 \mathrm{M} \mathrm{KCl} /$ buffer $\mathrm{Q}$; activity eluted at $\sim 0.4 \mathrm{M} \mathrm{KCl}$. Final working enzyme stocks (fraction VII) were taken from single fractions corresponding to the peak of activity. Samples were adjusted to $50 \%$ glycerol in buffer Q plus $50 \mathrm{~mm} \mathrm{KCl}$ using ultrafiltration units and stored at $-20^{\circ} \mathrm{C}$. A unit of RNase MRP activity is defined as the amount of enzyme that produces $50 \%$ product in a $25-\mu \mathrm{l}$ reaction volume containing 10 pmoles of the free RNA substrate at $37^{\circ} \mathrm{C}$ for $30 \mathrm{~min}$. Typical levels of purification ranged from 6700- to 9500 -fold over starting material (from $\sim 3$ grams of purified mitochondria). Purification and radiolabeling of the RNase MRP RNA from Mono $Q$ fractions were described previously /Chang and Clayton 1987a). RNase MRP purified from nuclear extracts had virtually the same chromatographic properties and behaved indistinguishably from mitochondrial preparations.

\section{Protease and nuclease inactivations of RNase MRP}

Proteinase K (Boehringer Mannheim) was added to a final concentration of $20 \mu \mathrm{g} / \mathrm{ml}$ in the RNase MRP reaction buffer containing $1-2$ units of RNase MRP and digested at $37^{\circ} \mathrm{C}$ for 30 min. As a negative control, the same concentration of proteinase $\mathrm{K}$ was added directly to an R-loop reaction mixture to confirm the absence of nucleases in the protease preparation. $\mathrm{Mi}$ crococcal nuclease (nuclease S7, Boehringer Mannheim) digestions were carried out by addition of 2 units of enzyme to a reaction mixture containing RNase MRP and supplemented with $1 \mathrm{mM} \mathrm{CaCl}_{2}$. Nuclease digestions were quenched by the addition of EGTA to a final concentration of $2 \mathrm{~mm}$. The presence of $1 \mathrm{mM} \mathrm{CaCl}_{2}, 2 \mathrm{~mm}$ EGTA, and the combination of $\mathrm{CaCl}_{2}$, EGTA, and micrococcal nuclease had no effect on RNase MRP activity.

RNase MRP reaction interference by antisense oligonucleotides

Oligonucleotides 2C and LRI are complementary to two different regions of the mouse RNase MRP RNA. Oligo $5.8 \mathrm{~S}$ is complementary to the mouse 5.8S rRNA sequence (GenBank accession no. K01367) and oligo $P$ is complementary to the mouse RNase P RNA (partial sequence, accession no. L08802). Sequences of oligonucleotides are as follows $\left(5^{\prime}\right.$ to $\left.3^{\prime}\right)$ : oligo $2 \mathrm{C}$, TCACTATGTGAGCTGACGGA (Chang and Clayton 1987b); oligo LRI, GGTCCGGGGACTTTCC; oligo 5.8S, CCACCGCTAAGAGTCG; oligo P, GTCTCAGACCTTCCC. Detritylated and lyophilized oligonucleotides /automated phosphoramidite chemistry, Protein and Nucleic Acid Facility, Stanford University Medical Center) were dissolved in TE buffer $(10 \mathrm{~mm}$ Tris at $\mathrm{pH} 7.4,1 \mathrm{~mm}$ EDTA) and resolved in $20 \%$ polyacrylamide $/ 8 \mathrm{M}$ urea gels and located by UV shadowing. Gel slices were soaked in elution buffer $[0.5 \mathrm{M}$ ammonium acetate, $10 \mathrm{~mm} \mathrm{Mg}$-acetate, $0.1 \%$ SDS (Sambrook et al. 1989)]. Eluted oligonucleotides were then precipitated with 3.5 volumes of ethanol for $12-16 \mathrm{hr}$ at $-20^{\circ} \mathrm{C}$. Oligonucleotides were then loaded on a Mono Q HR $5 / 5$ FPLC column at $10 \mathrm{~mm} \mathrm{NaOH}(\mathrm{pH} 12), 0.5 \mathrm{M} \mathrm{NaCl}$, washed with the same buffer, and eluted with a linear gradient to $1.0 \mathrm{M}$ $\mathrm{NaCl}$ in $10 \mathrm{~mm} \mathrm{NaOH}$. Pooled samples were concentrated and solution exchanged to TE in Centricon 10 ultrafiltration units (Amicon). Samples were finally passed through spin columns of Sephadex G-25 equilibrated in $10 \mathrm{~mm}$ Tris at $\mathrm{pH}$ 7.4. Quantitations of purified oligonucleotides were made optically (260 nm) assuming $20 \mu \mathrm{g} / \mathrm{ml}$ per unit absorbance (Sambrook et al. 1989).
Various concentrations of oligonucleotides were added to the reaction buffer containing a constant amount of RNase MRP; this mixture was equilibrated at $37^{\circ} \mathrm{C}$ for $15-30 \mathrm{~min}$ and substrate was then added to initiate cleavage reactions.

\section{Depletion of RNase MRP activity by immunoprecipitation}

Ten microliters of crude human serum from a patient with clinical psoriasis was passed through Sephadex G-50 in IP buffer $(0.2 \mathrm{M} \mathrm{KCl}, 20 \mathrm{~mm}$ HEPES, $1 \mathrm{~mm}$ EDTA, and $0.5 \mathrm{~mm}$ DTT). The filtered serum was then adsorbed on $\sim 50 \mu \mathrm{l}$ (wet volume) protein A (Staphylococcus aureus)-Sepharose (Pharmacia) as described previously (Karwan et al. 1991). After extensive washing of Sepharose-bound immunoglobulins with a total of $\sim 5 \mathrm{ml}$ wash buffer $(500 \mathrm{~mm} \mathrm{KCl}, 20 \mathrm{~mm}$ HEPES at $\mathrm{pH} 7.5,0.1 \%$ Nonident 40, $1 \mathrm{mM}$ PMSF, and $0.5 \mathrm{~mm}$ DTT), 10-20 units of RNase MRP was added and equilibrated for $1 \mathrm{hr}$ with gentle agitation at $4^{\circ} \mathrm{C}$. Thereafter, the slurry was transferred to a $0.2-\mu \mathrm{m}$ microtube filter and spun at $6000 \mathrm{rpm}$ in a microcentrifuge for $1 \mathrm{~min}$ at $4^{\circ} \mathrm{C}$. Filtered samples were concentrated and buffers changed in Centricon 30 units. Final samples were adjusted to standard RNase MRP reaction conditions. Serum from a normal subject was treated identically.

\section{RNA sequencing reactions and 3 '-end-group analysis}

End-labeled RNA was sequenced using base-specific ribonucleases $T_{1}, U_{2}$, Phy $M$, and RNase B. c. according to the supplier's protocol (Pharmacia). Approximately $10 \mu \mathrm{g}$ of unlabeled R loop was digested with 10 units of RNase MRP for $1 \mathrm{hr}$. After enzyme inactivation at $65^{\circ} \mathrm{C}$ for $10 \mathrm{~min}$, DNA in the processed R-loop sample was digested with 10 units of RNase-free DNase I for 15 $\min$ at $37^{\circ} \mathrm{C}$. The samples were phenol-extracted and passed through Sephadex G-25 and ethanol-precipitated. The RNA pellet was redissolved in $5 \mu \mathrm{l}$ of a radiolabeling cocktail containing $25 \mu \mathrm{Ci} 5^{\prime}\left[{ }^{32} \mathrm{P}\right] \mathrm{pCp}$ (DuPont, NEN), 10\% dimethylsulfoxide, 50 $\mathrm{mm}$ HEPES at $\mathrm{pH} 7.5,15 \mathrm{~mm} \mathrm{MgCl}, 50 \mu \mathrm{g} / \mathrm{ml} \mathrm{BSA}$, and $1 \mathrm{~mm}$ DTT and 0.2 units of bacteriophage T4 RNA ligase (New England Biolabs). Radiolabeled products were resolved in $5 \%$ polyacrylamide $/ 8 \mathrm{M}$ urea gels, and thereafter wet gels were exposed to film for $12-16 \mathrm{hr}$ at $4^{\circ} \mathrm{C}$. The species of interest were located, excised, and soaked in RNA elution buffer as described above. After precipitation with $5 \mu \mathrm{g}$ of carrier tRNA, the pellets were redissolved in $5 \mu \mathrm{l}$ of $50 \mathrm{~mm}$ sodium acetate at $\mathrm{pH} 4.6,1 \mathrm{~mm}$ EDTA, containing 8 units of RNase $T_{2}$ and digested for $2 \mathrm{hr}$ at $37^{\circ} \mathrm{C}$ (Silberklang et al. 1979). Two microliters of each digested sample was spotted on precoated cellulose thin-layer chromatography glass plates, air dried, and resolved in the first dimension with $5: 3$ (vol/vol) isobutyric acid and ammonium hydroxide $(0.5 \mathrm{M})$; and in the second dimension with $7: 3$ ( $\mathrm{vol} / \mathrm{vol})$ isopropanol to $\mathrm{HCl}(18.5 \%)$ (Nishimura 1979). Plates were dried and exposed to film for $72-120 \mathrm{hr}$ at room temperature without intensifying screens.

\section{Acknowledgments}

We thank Jackie Doda for technical assistance with mammalian cell lines. We also thank Gerry Shadel, Tim Brown, Alison Davis, Jan Paluh, David Garman, and Jin Shang for helpful comments and critical review of the manuscript. D.Y.L. is a Medical Scientist Training Program trainee of the National Institute of General Medical Sciences (GM07365-19). This investigation was supported by grant R37-GM33088-26 from the National Institute of General Medical Sciences to D.A.C.

The publication costs of this article were defrayed in part by 
payment of page charges. This article must therefore be hereby marked "advertisement" in accordance with 18 USC section 1734 solely to indicate this fact.

\section{References}

Asai, T. and T. Kogoma. 1994. D-loops and R-loops: Alternative mechanisms for the initiation of chromosome replication in E. coli. J. Bacteriol. 176: 1807-1812.

Baker, T.A. and A. Kornberg. 1988. Transcriptional activation of initiation of replication from the E. coli chromosomal origin: An RNA-DNA hybrid near oriC. Cell 55: 113-123.

Balakin, A.G., L. Smith, and M.J. Fournier. 1996. The RNA world of the nucleolus: Two major families of small RNAs defined by different box elements with related functions. Cell 86: 823-834.

Battey, J. and D.A. Clayton. 1980. The transcription map of human mitochondrial DNA implicates transfer RNA excision as a major processing event. J. Biol. Chem. 255: 1159911606.

Bennett, J.L. and D.A. Clayton. 1990. Efficient site-specific cleavage by RNase MRP requires interaction with two evolutionarily conserved mitochondrial RNA sequences. Mol. Cell. Biol. 10: 2191-2201.

Bibb, M.J., R.A. Van Etten, C.T. Wright, M.W. Walberg, and D.A. Clayton. 1981. Sequence and gene organization of mouse mitochondrial DNA. Cell 26: 167-180.

Brown, G.G., G. Gadaleta, G. Pepe, C. Saccone, and E. Sbisà 1986. Structural conservation and variation in the D-loopcontaining region of vertebrate mitochondrial DNA. I. Mol. Biol. 192: 503-511.

Chang, D.D. and D.A. Clayton. 1985. Priming of human mitochondrial DNA replication occurs at the light-strand promoter. Proc. Natl. Acad. Sci. 82: 351-355.

- 1987a. A mammalian mitochondrial RNA processing activity contains nucleus-encoded RNA. Science 235: 11781184.

- $1987 \mathrm{~b}$. A novel endoribonuclease cleaves at a priming site of mouse mitochondrial DNA replication. EMBO $J$. 6: 409-417.

Chang, D.D., W.W. Hauswirth, and D.A. Clayton. 1985. Replication priming and transcription initiate from precisely the same site in mouse mitochondrial DNA. EMBO I. 4: 15591567.

Chu, S., R.H. Archer, J.M. Zengel, and L. Lindahl. 1994. The RNA of RNase MRP is required for normal processing of ribosomal RNA. Proc. Natl. Acad. Sci. 91: 659-663.

Clayton, D.A. 1982. Replication of animal mitochondrial DNA. Cell 28: 693-705.

- 1994. A nuclear function for RNase MRP. Proc. NatI. Acad. Sci. 91: 4615-4617.

Côté, J. and A. Ruiz-Carrillo. 1993. Primers for mitochondrial DNA replication generated by endonuclease G. Science 261: 765-769.

Doersen, C.-J., C. Guerrier-Takada, S. Altman, and G. Attardi. 1985. Characterization of an RNase P activity from HeLa cell mitochondria. J. Biol. Chem. 260: 5942-5949.

Evans, M.J. and R.C. Scarpulla. 1990. NRF-1: A trans-activator of nuclear-encoded respiratory genes in animal cells. Genes \& Dev. 4: 1023-1034.

Forster, A.C. and S. Altman. 1990. Similar cage-shaped structures for the RNA components of all ribonuclease $\mathrm{P}$ and ribonuclease MRP enzymes. Cell 62: 407-409.

Fuller, C.W. and C.C. Richardson. 1985. Initiation of DNA replication at the primary origin of bacteriophage $\mathrm{T} 7$ by purified proteins. J. Biol. Chem. 260: 3185-3196.

Gillum, A.M. and D.A. Clayton. 1979. Mechanism of mitochondrial DNA replication in mouse L-cells: RNA priming during the initiation of heavy-strand synthesis. I. Mol. Biol. 135: 353-368.

Gold, H.A., J.N. Topper, D.A. Clayton, and J. Craft. 1989. The RNA processing enzyme RNase MRP is identical to the Th RNP and related to RNase P. Science 245: 1377-1380.

Huang, L., Y. Kim, J.J. Turchi, and R.A. Bambara. 1994. Structurespecific cleavage of the RNA primer from Okazaki fragments by calf thymus RNase HI. J. Biol. Chem. 269: 25922-25927.

Huber, H.E. and C.C. Richardson. 1990. Processing of the primer for plus strand DNA synthesis by human immunodeficiency virus 1 reverse transcriptase. J. Biol. Chem. 265: 10565-10573.

Itoh, T. and J. Tomizawa. 1980. Formation of an RNA primer for initiation of replication of ColEl DNA by ribonuclease $\mathrm{H}$. Proc. Natl. Acad. Sci. 77: 2450-2454.

Karwan, R., J.L. Bennett, and D.A. Clayton. 1991. Nuclear RNase MRP processes RNA at multiple discrete sites: Interaction with an upstream $G$ box is required for subsequent downstream cleavages. Genes \& Dev. 5: 1264-1276.

Lee, B., A.G. Matera, D.C. Ward, and J. Craft. 1996. Association of RNase mitochondrial RNA processing enzyme with ribonuclease $\mathrm{P}$ in higher ordered structures in the nucleolus: A possible coordinate role in ribosome biosynthesis. Proc. Nat1. Acad. Sci. 93: 11471-11476.

Lee, D.Y. and D.A. Clayton. 1996. Properties of a primer RNADNA hybrid at the mouse mitochondrial DNA leadingstrand origin of replication. I. Biol. Chem. 271:2426224269.

Li, K. and R.S. Williams. 1995. Cloning and characterization of three new murine genes encoding short homologues of RNase P RNA. I. Biol. Chem. 270: 25281-25285.

Lygerou, Z., P. Mitchell, E. Petfalski, B. Séraphin, and D. Tollervey. 1994. The POP1 gene encodes a protein component common to the RNase MRP and RNase P ribonucleoproteins. Genes \& Dev. 8: 1423-1433.

Lygerou, Z., C. Allmang, D. Tollervey, and B. Séraphin. 1996. Accurate processing of a eukaryotic precursor ribosomal RNA by RNase MRP in vitro. Science 272: $268-270$.

Masukata, H. and I. Tomizawa. 1990. A mechanism of formation of a persistent hybrid between elongating RNA and template DNA. Cell 62: 331-338.

Matera, A.G., M.R. Frey, K. Margelot, and S.L. Wolin. 1995. A perinucleolar compartment contains several RNA polymerase III transcripts as well as the polypyrimidine tract-binding protein, hnRNP I. J. Cell Biol. 129: 1181-1193.

Miller, D.L. and N.C. Martin. 1983. Characterization of the yeast mitochondrial locus necessary for tRNA biosynthesis: DNA sequence analysis and identification of a new transcript. Cell 34: 911-917.

Nishimura, S. 1979. Chromatographic mobilities of modified nucleotides, Appendix III. In Transfer RNA: Structure, properties, and recognition (ed. P.R. Schimmel, D. Söll, and J.N. Abelson), pp. 551-552. Cold Spring Harbor Laboratory, Cold Spring Harbor, NY.

Ojala, D., S. Crews, J. Montoya, R. Gelfand, and G. Attardi. 1981a. A small polyadenylated RNA 7S RNA, containing a putative ribosome attachment site, maps near the origin of human mitochondrial DNA replication. I. Mol. Biol. 150: 303-314.

Ojala, D., J. Montoya, and G. Attardi. 1981b. tRNA punctuation model of RNA processing in human mitochondria. Nature 290: 470-474.

Robertson, H.D., S. Altman, and J.D. Smith. 1972. Purification 
and properties of a specific Escherichia coli ribonuclease which cleaves a tyrosine transfer ribonucleic acid precursor. J. Biol. Chem. 247: 5243-5251.

Romano, L.J., F. Tamanoi, and C.C. Richardson. 1981. Initiation of DNA replication at the primary origin of bacteriophage $\mathrm{T} 7$ by purified proteins: Requirement for T7 RNA polymerase. Proc. Natl. Acad. Sci. 78: 4107-4111.

Sambrook, J., E.F. Fritsch, and T. Maniatis. 1989. Molecular cloning: A laboratory manual, 2nd ed. Cold Spring Harbor Laboratory Press, Cold Spring Harbor, NY.

Schmitt, M.E. and D.A. Clayton. 1993. Nuclear RNase MRP is required for correct processing of pre-5.8S rRNA in Saccharomyces cerevisiae. Mol. Cell. Biol. 13: 7935-7941.

Schmitt, M.E., J.L. Bennett, D.J. Dairaghi, and D.A. Clayton. 1993. Secondary structure of RNase MRP RNA as predicted by phylogenetic comparison. FASEB I. 7: 208-213.

Silberklang, M., A.M. Gillum, and U.L. RajBhandary. 1979. Use of in vitro ${ }^{32} \mathrm{P}$ labeling in the sequence analysis of nonradioactive tRNAs. Methods Enzymol. 59: 58-109.

Stark, B.C., R. Kole, E.J. Bowman, and S. Altman. 1978. Ribonuclease P: An enzyme with an essential RNA component. Proc. Natl. Acad. Sci. 75: 3717-3721.

Stohl, L.L. and D.A. Clayton. 1992. Saccharomyces cerevisiae contains an RNase MRP that cleaves at a conserved mitochondrial RNA sequence implicated in replication priming. Mol. Cell. Biol. 12: 2561-2569.

Tapper, D.P., R.A. Van Etten, and D.A. Clayton. 1983. Isolation of mammalian mitochondrial DNA and RNA and cloning of the mitochondrial genome. Methods Enzymol. 97: 426-434.

Virbasius, C.A., J.V. Virbasius, and R.C. Scarpulla. 1993. NRF-1, an activator involved in nuclear-mitochondrial interactions, utilizes a new DNA-binding domain conserved in a family of developmental regulators. Genes \& Dev. 7: 2431-2445.

Virbasius, J.V. and R.C. Scarpulla. 1994. Activation of the human mitochondrial transcription factor A gene by nuclear respiratory factors: A potential regulatory link between nuclear and mitochondrial gene expression in organelle biogenesis. Proc. Natl. Acad. Sci. 91: 1309-1313.

vonMeyenburg, K., E. Boye, K. Skarstad, L. Koppes, and T. Kogoma. 1987. Mode of initiation of constitutive stable DNA replication in RNase H-defective mutants of Escherichia coli K-12. J. Bacteriol. 169: 2650-2658.

Wong, T.W. and D.A. Clayton. 1986. DNA primase of human mitochondria is associated with structural RNA that is essential for enzymatic activity. Cell 45: 817-825.

$\mathrm{Xu}, \mathrm{B}$. and D.A. Clayton. 1995. A persistent RNA-DNA hybrid is formed during transcription at a phylogenetically conserved mitochondrial DNA sequence. Mol. Cell. Biol. 15: 580-589.

- 1996. RNA-DNA hybrid formation at the human mitochondrial heavy-strand origin ceases at replication start sites: An implication for RNA-DNA hybrids serving as primers. EMBO T. 15: 3135-3143. 


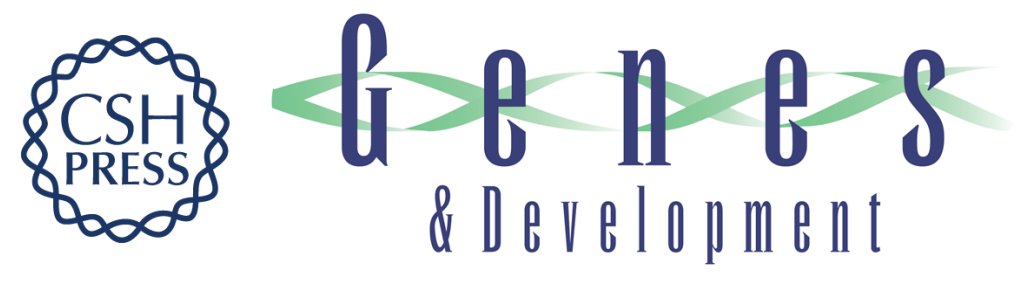

\section{RNase mitochondrial RNA processing correctly cleaves a novel R loop at the mitochondrial DNA leading-strand origin of replication.}

D Y Lee and D A Clayton

Genes Dev. 1997, 11:

Access the most recent version at doi:10.1101/gad.11.5.582

$\begin{array}{ll}\text { References } & \text { This article cites } 49 \text { articles, } 31 \text { of which can be accessed free at: } \\ \text { http://genesdev.cshlp.org/content/11/5/582.full.html\#ref-list-1 }\end{array}$

License

Email Alerting Receive free email alerts when new articles cite this article - sign up in the box at the top Service right corner of the article or click here.

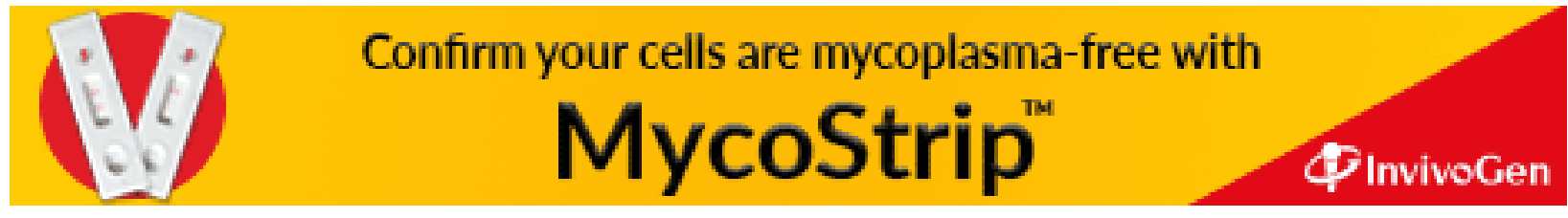

